\title{
Article
}

\section{Systems for technical refinement in experienced performers: The case from expert-level golf}

Carson, H.J., Collins, D., and MacNamara, Á.

Available at http://clok.uclan.ac.uk/12204/

Carson, H.J. ORCID: 0000-0002-3785-606X, Collins, D., ORCID: 0000-00027601-0454 and MacNamara, Á. ORCID: 0000-0002-8110-6784 (2013) Systems for technical refinement in experienced performers: The case from expertlevel golf. International Journal of Golf Science, 2 (1). pp. 65-85. ISSN 21687595

It is advisable to refer to the publisher's version if you intend to cite from the work.

For more information about UCLan's research in this area go to

http://www.uclan.ac.uk/researchgroups/ and search for <name of research Group>.

For information about Research generally at UCLan please go to http://www.uclan.ac.uk/research/

All outputs in CLoK are protected by Intellectual Property Rights law, including Copyright law. Copyright, IPR and Moral Rights for the works on this site are retained by the individual authors and/or other copyright owners. Terms and conditions for use of this material are defined in the policies page.

\section{CLoK}

Central Lancashire online Knowledge www.clok.uclan.ac.uk

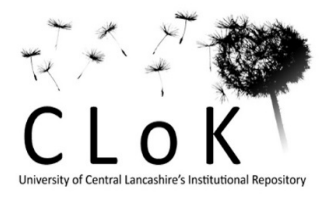


This is a pre-proof corrected manuscript as accepted for publication, of an article published in International Journal of Golf Science, (CHuman Kinetics, in August 2013, available online: http://journals.humankinetics.com/ijgs-back-issues/ijgs-volume-2-issue-1-august/systems-fortechnical-refinement-in-experienced-performers-the-case-from-expert-level-golf

6

7

8

9

10

\section{Systems for Technical Refinement in Experienced Performers: The case from expert-}

\section{level golf}

\author{
Howie J. Carson*, Dave Collins and Áine MacNamara
}

Institute for Coaching and Performance, University of Central Lancashire

*Correspondence concerning this paper should be addressed to Howie J. Carson,

25 Institute for Coaching and Performance, University of Central Lancashire, Preston, United

26 Kingdom, PR1 2HE.

27 E-mail: hjcarson@uclan.ac.uk 
Abstract

29

This paper provides an overview of current golf coaching practices employed with experts, when attempting to make changes to (i.e., refine) a player's existing technique. In the first of two studies, European Tour golfers $(n=5)$ and coaches $(n=5)$ were interviewed to establish the prevalence of any systematic processes, and whether facilitation of resistance to competitive pressure (hereafter termed "pressure resistance") was included. Study 2 employed an online survey, administered to 89 PGA Professionals and amateur golfers (mostly amateurs; $n=83$ ). Overall, results suggested no standardized, systematic, or theoretically considered approach to implementing technical change, with pressure resistance being considered outside of the change process itself; if addressed at all. In conclusion, there is great scope for PGA professionals to increase their coaching efficacy relating to skill refinement; however, this appears most likely to be achieved through a collaborative approach between coach education providers, researchers, and coaches. professionals, golf coaching, the Five-A Model. 
54

Systems for technical refinement in experienced performers: The case from expert-level golf Much research attention has focused on the learning of motor skills (e.g., Schmidt \& Bjork, 1992; Wulf, 2013). This has included theories of learning as a systematic process, distinguished by the learner progressing initially through a stage of acquiring broad features of the movement form, to eventually fixating or diversifying their movement repertoire depending on the environmental constraints dictated by the sporting context in which they perform (Gentile, 1972). In addition, an understanding of process markers or mechanisms, associated with the learning stages, for example cognitive structures changing from declarative to procedural in nature (Anderson, 1982) and coordination dynamics evolving from freezing to freeing of degrees of freedom (Bernstein, 1967), has enabled progression through these systematic stages to be assessed and monitored by the coach. In other words, a greater understanding of how a skill is developing, and therefore what might be predicted in terms of their performance, can be gained based on several mechanistic changes that occur within the individual.

Research has also investigated numerous coaching strategies or "tools" which, when applied, serve to facilitate different outcomes within the learning process. These have included such variables as feedback (Bruechert, Lai, \& Shea, 2003), demonstrations (Horn, Williams, \& Scott, 2002), and practice schedules (Goodwin \& Meeuwsen, 1996). As a result of this research, coaches should have sufficient knowledge to manipulate learning and practice environments to achieve specific, measureable outcomes (e.g., rapid acquisition or greater retention and transfer of a skill) depending on the realistic and desired goals of the learner, therefore supporting the need for effective coach decision-making (cf. Abraham \& Collins, 2011). 
Importantly, however, is the recognized gap between empirical evidence derived under laboratory conditions and its practical and comprehensive application within effective coaching environments (Porter, Wu, \& Partridge, 2010). In fact, recent research has shown high-level soccer coaches to possess low self-awareness of their coaching behaviors and link between declarative and procedural knowledge (Partington \& Cushion, 2013). Similarly, expert golf instruction has been reported to be largely intuitive with a lack of reference to (applied) scientific evidence-bases, whereby the primary sources of knowledge are derived from other coaches and previous experience (Schempp, Templeton, \& Clark, 1998). This is in contrast to current approaches adopted by other sport professions (e.g., sport psychologists), whereby practitioners are encouraged to draw upon different research findings when designing interventions with the aim of enabling specific outcomes. Such processes have been suggested as a way of "providing evidence-driven models for understanding, conceptualizing, assessing, and intervening with athletes" (Martindale \& Collins, 2007, p. 458). These can be considered under the ideas of professional judgment and decision making (PJDM; cf. Martindale \& Collins, 2005) and the construction of an epistemological decision making chain (Grecic \& Collins, 2010), which both highlight the need for coaches to be consciously aware of what they are doing and why they are doing it (cf. Martindale \& Collins, 2012). In this regard, it has been argued that previous research has used ill-defined criteria to define coaching expertise (Nash, Martindale, Collins, \& Martindale, 2012). These criteria have often included experience, positions held, and selection by others. What has not been assessed is the coach's ability to make use of a variety of information acquired to purposefully decide on, design, and facilitate different outcomes. If golf coaches were to employ these explicit and evidence-based decision making approaches, instead of solely or predominantly using intuition, they may have the potential to enhance practitioner effectiveness when considering the need to address unique 
characteristics of performers and an intended intervention outcome (e.g., long term and pressure resistant technical refinement, a rapid improvement in a learner's performance). Therefore, closing this research-practice gap would result in a higher-level of "applied knowledge" (cf. Martens, 1987, p. 54). Hence in this paper we stress the need to pull together different established bodies of knowledge, for instance sport psychology, motor control, and biomechanics, within the context of an applied coaching science.

Despite the significant pool of research relating to the stages of learning and associated mechanisms (i.e., cognitive and coordination changes), there is less attention within the literature concerning the refinement of skill for those performers who have already learned and successfully fixated or diversified their movement techniques but who now wish to adjust, refine, and execute this new version consistently within the context of a high-pressured competitive sporting environment. This indicates, therefore, that there is potential for not only a research gap to be filled, but at the same time an applied practice one as well.

While some studies have been conducted to explain effective methods used to facilitate refinement (e.g., Collins, Morriss, \& Trower, 1999; Hanin, Korjus, Jouste, \& Baxter, 2002), they have not always provided vital kinematic evidence or measures relating to movement control (e.g., variability; cf. Carson, Collins, \& Richards, in press) to verify the validity of such approaches. This is unfortunate since enabling successful and robust change to an expert performer's technique is an essential role for any top-level coach. Accordingly, knowledge on how this important but common task can be optimized should form a central component of a coach's and sport psychologist's armory.

To date, instead of studies addressing the need for effective skill refinement, a large amount of research with experts has focused on performing skills optimally (e.g., Bell \& Hardy, 2009), including attempts to prevent performance failure under pressure (Beilock, 
Bertenthal, McCoy, \& Carr, 2004; MacPherson, Collins, \& Morriss, 2008). For example, evidence supporting the optimal control of movement using subconscious and proceduralized memory structures has been examined experimentally using dual-task conditions (Beilock et al., 2004) and through the use of holistic rhythm-based cues in applied practice (MacPherson et al., 2008). In both cases, these studies highlight the need for strategies to prevent the explicit processing of movement constituents during times of competitive pressure. Unfortunately, these strategies are rarely conducted within the applied context of technical refinement where, considering the similarly influential "mental" involvement associated with the change (Smith, 2003), skill breakdown should be considered as an avoidable outcome.

Despite these shortcomings within academic research, anecdotal evidence suggests technical refinement to be common practice for coaches and players in sports such as golf that demand a high-level of motor skill (Bush, 2011; Ross, 2011). In fact, many studies have already used golf in an attempt to understand the complex nature of swing technique and the parameters governing its level of control in stressful situations (Beilock et al., 2004; Myers et al., 2008). Justification for the need of a scientific and evidence based approach in golf is exemplified by recent cases of skill failure, such as by Tiger Woods when returning to competition following a "technical rebuild" (Hayward, 2012). Therefore golf, with its demand for use of specific motor control processes and the high-pressure, naturalistic context in which the skill is performed, is an ideal platform to explore skill refinement.

Reflecting these considerations and the need to establish an updated perspective on the potential research-practice gap, the purpose of this paper was to provide an overview of the current practices employed in expert golf coaching, when attempting to make changes to a player's existing technique. In viewing both players and coaches as active agents within the 
coaching process, we sought to include the perspectives of each. We also recognized that strength could be gained by providing a holistic, as opposed to fragmented, approach to this exploratory study. Consequently this overarching aim was addressed in two linked stages. In study 1 we employed a qualitative approach to determine the extent to which (a) a systematic approach to technical change was apparent, and (b) whether pressure resistance was facilitated during the technical change process, if/when it existed. In study 2, a larger scale, mixed methods survey was conducted to investigate broader aspects relating to the circumstances and practicalities surrounding technical changes, including (a) reasons for undertaking technical change, (b) outcomes and concomitants underpinning successful and unsuccessful technical change, (c) methods implemented if/when pressure resistance was attempted, and (d) information sources used by players when changing their technique.

\section{Study 1}

Initially, it was important to explore the prevalence of a systematic process employed to bring about technical change, and whether pressure resistance was facilitated within this at the highest level of performance. Accordingly, we adopted an approach of using individual, indepth case studies with expert coaches and players, who were interviewed to provide a retrospective exploration of technical change

\section{Method}

\section{Participants}

For this initial investigation and evaluation of current practices, male golfers $(n=5)$ and coaches $(n=5)$ were selected based on the criteria that they played or coached on The European Tour (i.e., they were professionally ranked). Reflecting the expert nature of this sample, one of the players had been ranked European Number One, with three players being previous winners on The European Tour. Three of the coaches were accredited with "PGA Master Professional" status, the highest accolade held by a member of The Professional Golfers' 
Association of Great Britain \& Ireland (PGA) and the remaining two were England National coaches. In accordance with existing studies examining expert golf coaching by Schempp and colleagues (Schempp et al., 2004; Schempp, McCullick, Busch, Webster, \& Mason, 2006; Schempp et al., 1998), the coaches included in this study had a minimum of 10 or more years coaching experience. One of the criteria for being appointed a PGA Master Professional is a minimum duration of 15 years coaching experience; the remaining two England National coaches also had a minimum of 15 years coaching experience. Therefore, considering their status and years of experience, the coaches included within this study should be viewed as experts, at least as defined by recent literature.

\section{Interview Guide}

Before the commencement of the study, pilot interviews were carried out with PGA qualified coaches $(n=4)$ and low handicap golfers (handicap range $=2-5, n=3$ ). Feedback was sought from these participants concerning the interview schedule and process. Following this, a small number of changes were made to allow greater ease of memory retrieval and to improve the systematic flow of the process. During the interviews, participants were asked to recall exemplars of technical change that they had coached or undertaken as players within the last five years. This line of questioning included: (a) reasons underpinning technical change, (b) specific skills that were changed, (c) the process used to make the technical change, (d) methods used to test against competitive pressure, and (e) experiences of any subsequent technical failure. Probes were used, when necessary, to elicit greater detail of participant's experiences and to ensure a consistent depth of response across participants. The interview guide is available from the first author, upon request.

\section{Procedure}

Ethical approval was granted from the university's ethics committee and informed consent was obtained from all participants. All participants were approached following 
202

203

204

205

206

207

208

209

210

211

212

213

214

215

216

217

218

219

220

221

222

223

contact with The European Tour (preceding a tournament) or via a direct letter invitation. It was explained that participation was voluntary and anonymity assured. Semi-structured interviews were conducted with each participant in a quiet private location and at a time convenient to the participant. All participants were provided an introduction to the topic and the interview to help develop ease and rapport with the interviewer. Interviews lasted approximately 35 minutes, excluding introductory and setup periods employed to place participants at their ease and to ensure they were fully conversant with the approach.

\section{Data Analysis}

As a first step, each interview was listened to several times to fully apprehend its essential features before transcription as recommended by Sandelowski (1995). An inductive content analysis was conducted, using the data analysis program Atlas.ti., and using the guidelines as outlined by Côté, Salmela, Baria, and Russell (1993). This involved an initial scanning and tagging of quotes elicited from the transcriptions and organizing them into raw data themes. These raw data themes were then grouped together into lower-order themes based upon common features, until data analysis reached saturation. These themes were then grouped together under an umbrella theme, which represented the highest level of abstraction. On completion, a subsequent deductive analysis considered the raw data and umbrella themes against study 1's aims of "evidence for a systematic approach" and "facilitation of subsequent pressure resistance."

Several steps were taken to ensure the validity and trustworthiness of the data presented. Recognizing the risk for miscoding and misclassification of meaning units, a collaborative approach was taken. Two of the researchers, one of whom was blind to the research aims, collaborated during the coding process. When this process resulted in an analytic disagreement (less than $10 \%$ of data codes) both researchers presented their interpretations until a plausible explanation was agreed upon (Sparkes, 1998). 


\section{Results}

The results are presented in two sections reflecting the aims of this study. Firstly, the extent to which a systematic approach was apparent; and secondly whether pressure resistance was facilitated during the technical change process, if/when it existed (see Table $1)$.

\section{2}

\section{Systematic Approaches to Technical Change}

This theme probed the mechanisms and stages through which technical change was facilitated. To contextualize this against several recognized mechanisms of learning, this could include references to change in memory structures (conscious/subconscious) or coordination dynamics. We begin by highlighting the systems reported by coaches and players, and within this, explore the (lack of) consistency of approaches used across participants (inter-individual), followed by within participants (intra-individual).

Reported systems for technical change - inter-individual differences. Although nine participants reported how they implemented a systematic approach to technical change, these systems were inconsistent between individuals with regards to the number of stages employed and/or the mechanisms underpinning them. Exemplifying these different systematic approaches, one coach described a three stage system which considered the time of year and processes involved (psychological and task) with change in relation to the golfer's competitive requirements:

In the red zone [off season] it's going to be highly technical, so they are working to try and do something within their technique, trying to achieve something. If they are coming into the amber and green zone [season] it's going to be much more of a mixture between the same things, right, and performance, so we use a lot of shot shaping [hitting the golf ball with a curved flight] ... In the red zone you don't have to worry 
too much about what the ball is doing at that point... in the green zone it's more shot orientation rather than technique.

However, although another player also viewed technical change as reflecting the mental component involved, this consisted of only a two stage process:

In the first part of the change you are just concentrating and rehearsing what you are technically doing, really trying to drill that in. But when you start polishing off obviously you need to know how it's going to react under a bit of pressure and a bit of tournament mode, so you try and do that in your practice ... not thinking too much about technical things, just trying to get the job done really.

Reflecting this inconsistency, another coach again reported the psychological process involved with technical change, but described a four stage system involving progression along sequential "bays" (cubicles) at the driving range:

I have four bays in my academy. I have a bay that's called "I'm in construction" and then the next bay "I'm seeing it," players seeing it and feeling what their body does ... using mirrors a lot of the time, so seeing and feeling it and then the next bay we'd try and stand there and work on routines and starting points and shot shaping. Then the final bay would be out there, playing what they think is naturally, but now they've gone through all the learning process.

There were also inconsistencies in the mechanisms adopted during the technical change process. For example, rather than adopting psychological mechanisms, two coaches explained how technical change required physical repetition of movement (drilling), implying a one stage approach rather than progression through an evolving stage system. In these instances, coaches placed a significant emphasis on the neurophysiological processes, with this coach suggesting that to change you need to: 
Keep telling the brain what you want to do and not what you don't want to do, repetition, repetition, repetition. All of a sudden the brain is giving the messages that much quicker to the muscles, your muscles get tuned up to the movement you want to make every single time, if you did it every day you'd get better.

This was strongly corroborated by the other coach, explaining:

It has to be able to be done by the subconscious; it's too fast for it to be conscious thought. It's the repetitive action of the brain being able to send the messages backwards and forwards from me to the muscles and getting its information before the conscious bit is actually able to think clearly about what it's done in hindsight.

Again, reflecting the inconsistency of systems used between participants, some players and coaches offered greater insight about the explicit need for various analyses as a precursor to technical change, reflecting a more psychosocial approach. One coach highlighted the importance of understanding the decision-making process, suggesting: It's in that planning and discussing stage where you are trying to get out of them [the golfer] what they feel's happening and why it is, before we start to make the refinements, is it a technical thing? Is that technical problem because physically there's a slight problem? Otherwise it's just a series of compromises really.

Strengthening this process, the same coach discussed the necessity for assessment under different playing conditions, including under pressure, to evaluate the current need for technical change (as opposed to evaluating the pressure resistance of the technical change, see Facilitation of Pressure Resistance theme below): Before we go too far I like to put the player to the challenge, now that might not be a tournament, but that challenge might be that you [the player] don't want to lose ten pounds. It may be that you've got enough money that actually a thousand pounds is 
appropriate. So let's go and find somebody that you're going to play for a thousand pounds of your own money, so we try and recreate that pressure to see how it is.

Another shared view between those participants, describing the pre-change stages, was the requirement to understand the player-coach relationship and what was expected from each other's role. One player described a positive consultation with his coach before implementing technical change:

I worked with a guy called X [coach's name] and he approached it very differently. In the first sort of initial interview when we talked, it was like "well this is not an exact science, you're going to have your [movement] tendencies, you're never ever going to hit the ball perfect over and over again, but how do you look upon the game, what are the shots you want to get away from? How do you play when you play your best?" And we worked on that but it became a slower process and a process that I was more a part of.

Likewise, one coach emphasized the need for "buy in" (from the golfer) and honesty in their approach to try and gain commitment, especially with regards to their practice: What I actually believe is that the pupil has to buy into what the coach is going to tell them... I try to be honest with top players that want change to be quick, but they understand it takes time because when they've changed in the past. So I say "look, I need to know how much you are going to practice, you absolutely need to practice and play like this, otherwise it really is not going to happen at all."

In contrast to this approach, other coaches who did not explicitly include procedures to enable buy in or commitment attributed poor adherence toward training to the player's attitude. For example, one coach described two different types of golfer and their response to the practice environment: 
One's much more compliant to doing these types of things, one less compliant. So then if they don't buy into the things that they are trying to do, then they are probably not going to move it on as much. So again you're always kind of stuck with what the individual really kind of wants to do.

This coach further suggested that a particular golfer did not "have, I suppose, as much drive and determination to kind of shift the technique." Further support toward the viewpoint that commitment and adherence was determined by a player's attitude; another coach highlighted that "from a coaching point of view you are not always in as much control of some players because their agenda is not the same as yours."

Intra-individual differences in exemplar case studies. Although many of the participants detailed accounts of systematic approaches to implementing technical change, when probed it became apparent that individual participants were not consistent in their approach from case to case. Interestingly, very few of the participants reported this underpinning variance as related to individual needs and circumstances (i.e., a rationalized variation in approach due to client characteristics). Instead, this was portrayed as an expected and normal aspect of the technical change process.

A common example of this low internal consistency was the multidirectional nature of systems initially described, whereby stages were frequently returned to, despite formal progression. Illustrating this, one coach described a system progressing through red (off season), amber (pre-season), and green (season) stages, represented by specific training practices for different outcomes. However, he later said:

He [the player] would still do some of the work that we did in the winter time so that even within a green area, which is a highly competitive area, you can still have kind of red, amber sections within that week. 
Another coach offered a four stage account of a systematic process, describing a

unidirectional transition between sequences of bays at the driving range (as described previously), each with the aim of manipulating the task to elicit a particular direction of attentional focus. Later in the interview however, when probed about this process, he explained that it was not always consistently unidirectional, as the following conversation highlights:

Interviewer: Do they ever go back and forth from bay to bay?

Yeah, absolutely.

Interviewer: How long would the process of going from the first to the end bay be?

How long would it be? It could be four shots.

In a different example, one player commented on the unsystematic, but constantly novel (as opposed to multidirectional), approach used by their coach. This player described how technical change was "never constant, never a consistent way to go. It was always trying to find quick fixes that didn't quite work, 'try this, this'll work, try that'." Supporting our findings that systems were different between and also within individuals, this player initially described a process of "doing all your graft physically, so then mentally you've basically got to try and unscramble it" when he was working with another coach. However, this was contradicted when revealing how technical change was actually applied, which suggested a repetitive cycle between "unscrambled" and change states:

You know most of the stuff that I do is repetitive, so to learn all the new good stuff that I have done, you know I'll always go back over the same ground if you like, so you know it's all repeating myself in a way.

Another way in which systems were internally inconsistent related to their incompletion. For instance, one player described a two stage system that started off as very technical in 
nature, concentrating mainly on the positioning within the technique. Following this stage, the player described how practice should be made more competitive to test the new technique under pressure and remove much of the conscious thought about the control of action. In the case of this player, the system failed to progress to the second stage. As a further illustration of the incomplete systems employed by the participants, there was no evidence of the players' making the reported technical change resistant to pressure the reported successful technical change. After probing to find out whether anything was implemented to bring about pressure resistance for a reported successful technical change, he retrospectively reflected and replied: "No not really, I think it was a case of really committing to what I was doing and in the first few tournaments I didn’t because I was a bit anxious.”

\section{Facilitation of Pressure Resistance}

This theme aimed to explore the methods employed to bring about pressure resistance when making a technical refinement. We were also interested in any additional elements of practice which could have been used, for instance testing against the symptoms of pressure.

Within the processes reported, none of the participants systematically included a stage to facilitate pressure resistance. However, it is worth exploring what participants did mention with regards to current practice, as players and coaches were clearly aware of the impact of pressure and its prevalence when implementing technical refinement.

Remedial practices. Participants reporting pressure resistant practices adopted a remedial as opposed to proactive approach. In other words, it was not until the technique went wrong under pressure that resistance was addressed. This approach was often referred to as "responding well to failure," summarized by one player describing how "every golfer is going to hit bad shots. That's not the problem; the problem is how to react to the bad shots and how to get yourself back as quick as possible." A common approach reported was to provide reassurance to the player that the technique was still attainable despite 
demonstrating poor execution during competition. One coach emphasized the important psychological impact this had on players' confidence: "That might mean explaining, it might be showing them on video exactly what's happening so they can see exactly what they are doing. So then that gives them confidence to say 'ok well the technique hasn't changed that much'." Another coach employed a more collaborative monitoring approach to reassure the player, where both coach and player recorded his actions and/or emotions in a diary during competition, followed by: ... Sitting him down and going through his round and say "you played this shot, what were you thinking? So tell me about it." That's why I like to do these zones [three holes at a time] when they come in they write it down and they go "I felt nervous to begin with" and I can confirm he looks edgy or he doesn't, and that reaffirms to me what he says I saw. So sometimes I might write a few things down and say "oh look I saw that."

In both cases, coaches, in particular, reported an approach of providing constant feedback, mainly in between competitions, reflecting the cyclical and multidirectional nature of technical change systems. Indeed, this was supported by players when they described the drills they did during practice:

You've always got to keep refining what you're doing and make sure the old stuff [technique] won't come in. I think to a certain degree you've always got that old stuff in you and you've always got to work on it probably for the whole of your career.

Many of the players described how they used a different, on-course, strategy which involved the manipulation of attentional load and direction. As before, however, there was significant variation in how this strategy was employed across individuals. For example, 
some participants highlighted the use of swing cues or thoughts to remind them of what they were working on to change, as this player explains:

There's always got to be a key thought with whatever shot you're trying to do. You may pick just one swing thought so you'd say "well it's the takeaway or it's the feeling at the top of the backswing or it's the pushing into the ground on the way down," you pick one swing thought out of all the different things that you have been working on.

Other players advocated more of a holistic feeling toward the action, attempting to remove conscious thought toward individual aspects of the swing, exemplified by one coach when commenting on a player's experience and the mental focus they should adopt: "I can actually feel my swing, I'm more in tune with my swing, I can feel the shot, I can play the shot." Another player described this approach as finding "feelings that are more connected to bigger muscles and to the full motion, rather than little right finger's going to do this or that." In contrast, some said they adopted an external focus to try and not "worry about the swing at all, I never think about the swing then [during failure] I just try and pick my target and hit it." Lastly, supporting the use of mental skills, one player commented on his level of commitment and how being more committed to executing the skill helped him overcome an initially poor return to competition: “the first few tournaments I didn't [commit] because I was a bit anxious, but full on commitment was the key really.”

\section{Brief Discussion}

The aim of study 1 was to provide data which explored, at the highest level, the extent to which (a) a systematic approach was apparent, and (b) whether pressure resistance was facilitated during the technical change process, if/when it existed, when attempting to make changes to a player's existing technique. In addressing these aims, clear conclusions have emerged. 
Coaches and players at this level do not describe (or presumably employ) standardized approaches when describing systems for technical change. Considering the dearth in research toward this practice, and lack of recognition toward any formal "ologies" (Abraham, Collins, \& Martindale, 2006) which may have informed their practice, it is likely that systems had been derived from experience, supporting the earlier mentioned researchpractice gap. Indeed, if the nature of expert coaching is based on intuition (cf. Schempp, McCullick, \& Mason, 2006), this would imply a low affordance to engage in an informed but dynamic process of PJDM; that is, to understand, conceptualize, appropriately assess, and deliver interventions targeted at specific outcomes (Martindale \& Collins, 2007), but that are informed by applied and theoretical research. Furthermore, the intra-individual inconsistency indicates potential rationalization on a post hoc basis, with little or no evidence of an epistemological chain apparent ("I want this, therefore ..."). On this basis, it is possible that European Tour golfers are, more often than not, in a permanent state of technical change, or prevention of the "old" version, whereby knowledge of such practice is guided more by evidence of optimal performance states (as opposed to change). As a result, the frequently apparent inability to reautomate the refined skill and ensure that it is resistant to competitive pressure is unsurprising.

Based on the findings from study 1, the purpose of this study was to investigate broader aspects relating to the circumstances and practicalities surrounding technical changes. In doing so, this study aimed to provide quantitative evidence for assessing the current knowledge and practices used in golf, and to identify any considerations made toward technical change for players with highly fixated movements. Specifically, we were interested in the following areas (a) reasons for undertaking technical change, (b) outcomes and concomitants underpinning successful and unsuccessful technical change, (c) methods 
467

implemented if/when pressure resistance was attempted, and (d) information sources used by players when changing their technique.

\section{Methods}

\section{Participants}

Eighty-nine golfers from the United Kingdom took part in this study, comprising of PGA Professional golfers/coaches ( $n=6$; all professional so no current handicap, however all possessed a 4 or lower handicap upon turning professional) and amateurs ( $n=83$, mean handicap $=2.2, S D=2.2$, range $=+4-5$ ). Ethical approval was granted by the university's ethics committee before conducting the study.

\section{Procedures}

Survey development. Nine initial questions relating to the four areas (a)-(d) within study 2 were derived from the interview matrix used in study 1 . Multiple choice lists, including the option of "other, please state," were generated (for questions related to areas $[\mathrm{a}]-[\mathrm{c}])$ from the inductive analysis reported in study 1 , and were further informed by two of the authors; one a PGA Professional Golf Coach and the other a highly experienced consultant in both developmental and expert level sport. These questions enabled multiple answers per participant, as well as offering the opportunity to provide qualitative responses. A draft survey was then reviewed by an expert panel (none of whom were authors of the paper; cf. Fraenkel \& Wallen, 2000; Wiersma, 2001) consisting of a PGA Professional Golf Coach, an experienced educator in physical education and sport coaching, and a researcher in coaching with experience in golf; the expert panel provided feedback about the clarity and usefulness of the questions. Following revisions, the draft survey was returned to the expert panel: all were satisfied with the revisions to the questionnaire. Cognitive interviews (Willis, DeMatio, \& Harris-Kojetin, 1999) were then conducted with five participants representing the intended skill level for this survey. This was performed to remove any misunderstandings, inconsistencies, 
492

inappropriate response options, and to expand the process performed by the expert panel.

Following this step, five items were reworded and/or provided with an example for greater clarity and four items were subsequently added to two of the multiple choice questions.

Data collection and analysis. The survey was distributed by e-mail to 115 golf club secretaries within the United Kingdom, requesting that it be forwarded to any member of their golf club holding a handicap equal to or less than five. Participants received an email explaining the aims of the study, why it was being conducted and an electronic link to the survey using the tool SurveyMonkey (www. surveymonkey.com). Accordingly, all data were anonymous. The survey received a total of 123 attempted responses; however this was reduced to 89 submissions due to incomplete submissions (i.e., a failure to complete the questionnaire). Termination point for this survey was decided when response patterns reached stable levels (i.e., percentage response levels stayed the same despite an increase in responses, $\sim 30 \%$ of total submissions). Following closure of the survey, data were transferred to a Microsoft Excel 2010 spreadsheet for further analysis. Open-ended responses were coded and categorized using the same approach described in study 1 and this also enabled quantification of response frequency.

\section{Results and Brief Discussion}

\section{Reasons for Undertaking Technical Change}

Reasons underpinning previously attempted technical changes were varied among the participants. The most frequent reasons included the identification of a key weakness in specific technique (74.2\%) and the occurrence of poor performance/critical incidence(s) (66.3\%), while almost half of the participants suggested they had tried to further "perfect" the technique (49.4\%). The decision to change technique was most frequently reported as a shared decision between the coach and player (36\%), compared with only the coach $(28.1 \%)$, or the player (18\%) alone making the decision. Other reported reasons included a 
517

demand from an upcoming course $(22.2 \%)$, injury prevention/remedy $(15.7 \%)$, and regaining confidence $(1.1 \%)$, while a small percentage reported that they "did not know" why they decided to make a technical change (2.2.\%).

\section{Outcomes and Concomitants Underpinning Successful and Unsuccessful Technical}

\section{Change}

Participants were asked about both successful (i.e., the technical change occurred as planned and within the expected time scale) and unsuccessful (i.e., failure to achieve the specific movement pattern before aborting it, or it took longer than expected) technical change and the concomitants (e.g., feeling confident, technique regressed, technique worked well in competition) underpinning both processes.

Successful technical change. Psychosocial concomitants were reported most frequently as being beneficial toward the technical change outcome. The most common factor reported was realizing/understanding what was required to change (88.8\%), followed by feeling motivated to change technique (57.3\%), and being confident that technical change would occur $(33.7 \%)$. Interestingly, few participants reported the execution of the skill itself as being of importance, with only $19.1 \%$ reporting being able to perform the new technique in the competitive environment, and $15.7 \%$ acknowledging easy transfer to the golf course as underpinning successful technical change. What these latter results imply is that golfers do not consider these outcomes as a primary focus to understanding their technical development. Instead, psychological factors associated with the experience are viewed as more influential. Such a lack of focus on performance outcomes, and the processes through which they may best be accomplished, serve to support findings from study 1 and may ultimately limit the effectiveness of any technical change process and the decisions underpinning the approach taken. 
Unsuccessful technical change. In comparison with successful technical changes,

542

543

544

545

546

547

more participants recognized problems relating to skill execution as a key criterion of unsuccessful technical change; however, responses still remained considerably low.

Supporting the remedial practices following technical failure described in study 1 , over half of the participants reported that the technique regressed back to the old version (51.7\%), $33.7 \%$ stated the technique did not work under pressure, $22.5 \%$ suggested that technical change did not solve the problem, and $10.1 \%$ of participants said that they could not perform the new version at all. What these results suggest is that participants are slightly more aware of the consequences relating to technique when it goes wrong, as opposed to when it does not. In contrast to the responses to successful technical change, participants recognized low confidence levels as a cause of unsuccessful technical change (40.4\%), whereas high motivation (16.9\%), or commitment (15.7\%) were less well attributed toward the technical change outcome.

\section{Methods for Promoting Pressure Resistance}

The most frequently reported method for promoting pressure resistance was repetition of the movement $(22.5 \%)$, supporting the qualitative evidence reported in study 1. Similar to study 1 , some participants $(9 \%)$ reported using skills tests to promote pressure resistance. However, it is questionable as to whether these simply test the outcome of a “challenge," or actively promote resistance to pressure. Other reported methods included mental, behavioral, and physical practices, although each of these were reported by between only $1.1-5.6 \%$ of participants (see Table 2 ).

Reflecting the findings from study 1 , the response rate $(45 \%)$ to this open-ended question further suggests that pressure resistance is not a common feature of training when undergoing technical change. In addition, advocating repetition of movement as a method for promoting pressure resistance can be questioned as ill-informed and certainly not 
evidence-based, since studies have found repetition, or blocked practice, to result in low performance (distinct from studies on acquisition) transferability among skilled performers (e.g., Hall, Domingues, \& Cavazos, 1994), which would imply also to under pressure.

\section{Information Sources for Guiding Technical Change}

Results indicated the majority of participants to have sought advice from a PGA

Professional Golf Coach (66.3\%). The efficacy of this approach is questionable; however, since the findings in study 1 suggest that different coaches offer different guidance toward technical change. Eleven percent of participants specified that they had consulted golf specific instructional media such as books or videos, which was equal to the number of participants seeking advice from significant others, for example family members or friends. Four and one half percent of participants reported that they were self-informed when implementing technical change and, suggestive of not seeking any guidance, $29.2 \%$ did respond to this question. Despite the majority (although still low) of responses being predictable, considering the conventional role of a sports coach to expert performers, it is interesting that no participants had worked at a multi if not interdisciplinary level when implementing technical change-for example, the golfer and coach consulting with a sport psychology or motor control specialist, perhaps facilitated through attendance at a professional development course. This may reflect a number of reasons, including a lack of service providers available, awareness of service providers by the coaches or players, but also perhaps a resistance to use other's knowledge when developing experts, where this may be perceived by the coach to result in role conflict and therefore, less beneficial to the process (cf. Reid, Stewart, \& Thorne, 2004). The simple point is that some form of education is needed to learn what you do not know and thus, what needs referral.

\section{General Discussion}


The purpose of this paper was to provide an overview of the current practices

591

592

593

594

595

596

597

598

599

600

601

602

603

604

605

606

607

608

609

610

611

612

613

614

employed with experts, when attempting to make changes to a player's existing technique.

Results from both studies indicate little consensus or evidence of a scientifically-based system to best conduct such practices; nor do golfers appear to actively facilitate pressure resistance during the process. One main finding of practical and social importance was the status and influence of the PGA Professional Golf Coach as a source of information when undertaking a technical change. Therefore, supporting our earlier statement that knowledge on how this important but common task can be optimized should form a central component of a coach's armory.

Addressing this problem against current literature, there are two potential theoretically derived resolutions on offer. The first presents itself as an extension from the already existing theory of implicit motor learning (Masters, 1992; Rendell, Farrow, Masters, \& Plummer, 2011). In brief, implicit motor learning posits that skills learned without the use of conscious processing (i.e., without explicit knowledge compilation; cf. Fitts \& Posner, 1967; Schmidt \& Bjork, 1992) will remain robust under pressure due to an absence of declarative knowledge available to reinvest in, which would serve to disrupt the automaticity (subconscious control) of movement execution under pressure. For any motor skill, automatic execution relies on largely subconscious control which, in turn, enables attention to be directed toward detailed environmental and/or task features serving to enhance action planning. In golf, this is a particularly important feature of execution due to the demand on a player to respond to different environmental and task conditions with each shot. As such, implicit motor learning suggests both a system to enable technical change and a method for promoting pressure resistance; however, empirical data has yet to be provided for its use with high-level performers. Indeed, providing foresight, Gabbett and Masters (2011) recently suggested, "that it is simply not feasible for a performer to always employ the implicit motor 
615

learning paradigms that have been developed and validated in experimental laboratories" ( $\mathrm{p}$. 569). This suggests, therefore, that previously reported results using this paradigm may be subjected to specific experimental effects. Consequently, the application of implicit motor learning to skill refinement awaits future investigation. Based on the findings presented in this paper, none of the participants reported this method to enable technical refinement. Alternatively, Carson and Collins (2011) recently proposed a literature-derived systematic coaching tool, the Five-A Model. In contrast to implicit motor learning, the Five-A Model explicitly distinguishes between refinement, promoting optimal performance states, and learning or acquiring skills (cf. Bernstein, 1967; Fitts \& Posner, 1967). Specifically, it aims to facilitate optimal, permanent, and pressure resistant technical changes to already existing, long practiced, automatic movement skills, underpinned mechanistically by progressive stages. This begins with calling the desired movement into consciousness (Awareness stage) as a means of "driving a wedge" between the current and desired movement pattern. Such a need for this initially explicit stage is supported by numerous research disciplines such as neuroscience (Mercado, 2008), behavior, and coordination change (Bar-Eli, 1991; Kostrubiec, Tallet, \& Zanone, 2006), where this has been found to be essential in preventing an initial return to the existing (automatic) movement/behavior pattern. Elements of this practice could be derived from study 1 as performers thinking consciously about the aspect of the skill requiring refinement. Most participants reported the need for some form of awareness during training. Following, gradual modification or shift in the movement is facilitated (Adjustment stage), before undergoing the (Re)Automation stage to actively promote a more subconscious, and therefore optimal, level of control for high-level performers. In contrast to the Awareness stage, these two stages were not explicitly addressed by the participants when reporting on applied exemplars. This is highly likely to explain the lack of success in securing (making permanent) the desired technical changes made. In 
addition to these mechanistic underpinnings intended to bring about permanency, the model

641 also benefits by recommending an individually tailored approach, accommodating for the dynamic state of the performer, skill being refined, and environmental context in which it is to be performed; ensuring application for both fixated and diversified skills. Again, such individual consideration among participants was lacking. Moreover, the Five-A Model recognizes the impact of psychosocial concomitants (e.g., buy in, confidence, motivation, and trust) that are present during any human process of development or change, especially within the applied and competitive context of expert-level sport. Accordingly, as an essential precursor to change, the Analysis stage addresses issues such as the need to change, as opposed to increase consistency, the most effective kinematic direction for change, and to establish athlete buy in. This was reported by several of the players and coaches before implementing technical change; however there was less indication of this in study 2 when describing the reasons for implementing technical refinement which, would have been implied by a shared decision making process. Likewise, after having re-established subconscious control, the Assurance stage provides necessary practices such as combining high technical challenge with physical exertion (Collins et al., 1999) to enhance attentional control, confidence, and a "screening" off from symptoms (e.g., somatic and cognitive anxiety, self-focus) associated with "choking" under pressure (see Hill, Hanton, Matthews, \& Fleming, 2010 for a review). While many in study 1 mentioned some of these practices, as discussed earlier, this was remedial following technical failure as opposed to proactive within a systematic approach.

The low response rate and typical methods reported in study 2 suggest that pressure resistance is less well addressed at the elite amateur level, perhaps for reasons associated with competitive circumstances. An obvious and advantageous element of this model is its representativeness to the applied setting (i.e., interdisciplinary perspective). As such, it is 
unsurprising that some of these elements were mentioned by most of the participants, either when describing systems or applied exemplars, albeit most attention was paid to psychological elements as opposed to training design for instance. What is also clear from these data are the current inability to appropriately sequence and complete the stages in order. As such, and supported by the survey results relating to information sources for guiding technical change, guidance from a sport science/motor control expert would seem an appropriate addition to any existing coaching support. Due to the model's recent conception, empirical testing in its entirety is yet to be reported (cf. Carson et al., in press). However, future directions are clear if resolution is to be found between such dichotomized training proposals. Not only is testing between the Five-A Model and implicit motor learning required, but also against existing coaching practice, if either proposals are to be proven to enhance current approaches.

A limitation of these studies was the reliance of retrospective recall. It is appreciated that players and coaches may not keep records of training; however arguably, if knowledge of a systematic approach did form an element of a coach's declarative knowledge base, this should serve as a sufficient retrieval cue. To confirm this relationship between declarative and procedural knowledge, future studies may wish to employ a more longitudinal and mixed methods approach, including elements of coach observation to confirm what is reported. In addition, the findings of both studies could be subjected to cultural differences when considering the role of different national governing bodies across the world in providing coach education. In this regard, future studies may wish to include coaches who are training and operate from different geographical locations.

From a practical standpoint, it must be recognized that as research-practitioners we are constantly searching for new methods to positively impact on performance. Fundamentally, efforts to improve current practices should be driven to ensure that applied science support to performers 
690

691

692

693

694

695

696

697

698

699

700

701

702

703

704

705

706

707

708

709

710

711

712

713

714

is both impactful and relevant to the challenges which they face. As such, methods should address "real-world" issues, be well-grounded in theory and research, evaluated to high standards, and only then disseminated as a new approach. Supporting this view, the current paper forms part of ongoing research aimed to address the significant gap in current sport psychology/coaching research, knowledge, and practice relating to successful skill refinement. In doing so, this paper serves to contextualize both theoretical and applied knowledge, acting as an informed "stepping stone" for researchers/practitioners before testing against and between new hypotheses/models. Such a step is, we feel, essential to provide vital information relating to the pertinent and unique challenges (e.g., expectations from coaches and players, social factors) related to working within a specific discipline, in this case golf. Accordingly, data can be interpreted in a manner which helps facilitate refinement by not only detailing elements of effective practice but also contrasting these with those less efficacious ones; something even scarcer within the applied literature! Finally, if applied research is to receive the attention and credit it deserves, we need to make sure it is rigorous and constantly judged against a benchmark of what is currently being offered by applied practice, something that this paper has provided.

In conclusion, this paper has highlighted the current gap in knowledge and practice when attempting to make changes to a player's existing technique among expert amateur and European Tour level golfers and coaches. Consequently, we have established an urgent need for development in this area from both a coach education and research perspective. While recent research on this issue are clearly in their early stages of development and/or application (Carson \& Collins, 2011; Carson et al., in press; Gabbett \& Masters, 2011), it is hoped, and indeed we recommend, that efforts to bring about research informed coaching will be collaborative in nature between sport psychologists/scientists, coach educators, and coaches not only in golf, but across numerous sport and performance domains. 


\section{References}

716

717

718

719

720

721

722

723

724

725

726

727

728

729

730

731

732

733

734

735

736

737

738

Abraham, A., \& Collins, D. (2011). Taking the next step: Ways forward for coaching science. Quest, 63, 366-384.

Abraham, A., Collins, D., \& Martindale, R. (2006). The coaching schematic: Validation through expert coach consensus. Journal of Sports Sciences, 24, 549-564.

Anderson, J. R. (1982). Acquisition of cognitive skill. Psychological Review, 89, 369-406.

Bar-Eli, M. (1991). On the use of paradoxical interventions in counseling and coaching in sport. The Sport Psychologist, 5, 61-72.

Beilock, S. L., Bertenthal, B. I., McCoy, A. M., \& Carr, T. H. (2004). Haste does not always make waste: Expertise, direction of attention, and speed versus accuracy in performing sensorimotor skills. Psychonomic Bulletin \& Review, 11, 373-379.

Bell, J. J., \& Hardy, J. (2009). Effects of attentional focus on skilled performance in golf. Journal of Applied Sport Psychology, 21, 163-177.

Bernstein, N. A. (1967). The coordination and regulation of movements. Oxford: Pergamon Press.

Bruechert, L., Lai, Q., \& Shea, C. H. (2003). Reduced knowledge of results frequency enhances error detection. Research Quarterly for Exercise and Sport, 74, 467-472.

Bush, J. (2011). What they said: Graeme McDowell Retrieved 5 January, 2012, from http://www.pgatour.com/2011/r/05/13/mcdowell-transcript/index.html

Carson, H. J., \& Collins, D. (2011). Refining and regaining skills in fixation/diversification stage performers: The Five-A Model. International Review of Sport and Exercise Psychology, 4, 146-167. doi: 10.1080/1750984x.2011.613682

Carson, H.J., Collins, D., \& Richards, J. (in press). Intra-individual movement variability during skill transitions: A useful marker? European Journal of Sport Science. 
Collins, D., Morriss, C., \& Trower, J. (1999). Getting it back: A case study of skill recovery in an elite athlete. The Sport Psychologist, 13, 288-298.

Côté, J., Salmela, J. H., Baria, A., \& Russell, S. J. (1993). Organizing and interpreting unstructured qualitative data. The Sport Psychologist, 7, 127-137.

Fitts, P. M., \& Posner, M. I. (1967). Human performance. California: Brooks/Cole Publishing Company.

Fraenkel, J. R., \& Wallen, N. E. (2000). How to design and evaluate research in education. New York: McGraw-Hill.

Gabbett, T., \& Masters, R. (2011). Challenges and solutions when applying implicit motor learning theory in a high performance sport environment: Examples from Rugby League. International Journal of Sports Science and Coaching, 6, 567-575.

Gentile, A. M. (1972). A working model of skill acquisition with application to teaching. Quest, 17, 3-23.

Goodwin, J. E., \& Meeuwsen, H. J. (1996). Investigation of the contextual interference effect in the manipulation of the motor parameter of over-all force. Perceptual and Motor Skills, 83, 735-743.

Grecic, D., \& Collins, D. (2010). Discovering golf’s innermost truths: A new approach to teaching the game - A commentary. International Journal of Sports Science \& Coaching, 5, 133-137.

Hall, K. G., Domingues, D. A., \& Cavazos, R. (1994). Contextual interference effects with skilled baseball players. Perceptual and Motor Skills, 78, 835-841.

Hanin, Y., Korjus, T., Jouste, P., \& Baxter, P. (2002). Rapid technique correction using old way/new way: Two case studies with Olympic athletes. The Sport Psychologist, 16, 79-99. 
Hayward, P. (2012, April 8). The Masters 2012: Tiger Woods reveals the common touch as fairytale takes a scary twist, The Telegraph. Retrieved from http://www.telegraph.co.uk/sport/golf/mastersaugusta/9189766/The-Masters-2012Tiger-Woods-reveals-the-common-touch-as-fairytale-takes-a-scary-twist.html

Hill, D. M., Hanton, S., Matthews, N., \& Fleming, S. (2010). Choking in sport: A review. International Review of Sport and Exercise Psychology, 3, 24-39.

Horn, R. R., Williams, A. M., \& Scott, M. A. (2002). Learning from demonstrations: The role of visual search during observational learning from video and point-light models. Journal of Sports Sciences, 20, 253-269.

Kostrubiec, V., Tallet, J., \& Zanone, P.-G. (2006). How a new behavioral pattern is stabilized with learning determines its persistence and flexibility in memory. Experimental Brain Research, 170, 238-244.

MacPherson, A. C., Collins, D., \& Morriss, C. (2008). Is what you think what you get? Optimizing mental focus for technical performance. The Sport Psychologist, 22, 288303.

Martens, R. (1987). Sience, knowledge, and sport psychology. The Sport Psychologist, 1, 2955.

Martindale, A., \& Collins, D. (2005). Professional judgment and decision making: The role of intention for impact. The Sport Psychologist, 19, 303-317.

Martindale, A., \& Collins, D. (2007). Enhancing the evaluation of effectiveness with professional judgment and decision making. The Sport Psychologist, 21, 458-474.

Martindale, A., \& Collins, D. (2012). A professional judgment and decision making case study: Reflection-in-action research. The Sport Psychologist, 26, 500-518. 
Masters, R. S. W. (1992). Knowledge, knerves and know-how: The role of explicit versus implicit knowledge in the breakdown of a complex motor skill under pressure. British Journal of Psychology, 83, 343-358.

Mercado, E., III. (2008). Neural and cognitive plasticity: From maps to minds. Psychological Bulletin, 134, 109-137.

Myers, J., Lephart, S., Tsai, Y.-S., Sell, T., Smoliga, J., \& Jolly, J. (2008). The role of upper torso and pelvis rotation in driving performance during the golf swing. Journal of Sports Sciences, 26, 181-188.

Nash, C., Martindale, R., Collins, D., \& Martindale, A. (2012). Parameterising expertise in coaching: Past, present and future. Journal of Sports Sciences, 30, 985-994.

Partington, M., \& Cushion, C. (in press). An investigation of the practice activities and coaching behaviors of professional top-level youth soccer coaches. Scandinavian Journal of Medicine \& Science in Sports, n/a-n/a. doi: 10.1111/j.16000838.2011.01383.x

Porter, J. M., Wu, W. F. W., \& Partridge, J. A. (2010). Focus of attention and verbal instructions: Strategies of elite track and field coaches and athletes. Sport Science Review, 19, 77-89.

Reid, C., Stewart, E., \& Thorne, G. (2004). Multidisciplinary sport science teams in elite sport: Comprehensive servicing or conflict and confusion? The Sport Psychologist, $18,204-217$.

Rendell, M. A., Farrow, D., Masters, R., \& Plummer, N. (2011). Implicit practice for technique adaptation in expert performers. International Journal of Sports Science and Coaching, 6, 553-566.

Ross, H. (2011). Woods couldn't "make it happen". The Tour Report Retrieved 23 May 2011, from 

couldnt-make-it-happen/

Sandelowski, M. (1995). Qualitative analysis: What it is and how to begin. Research in Nursing and Health, 18, 371-375. doi: 10.1002/nur.4770180411

815

Schempp, P., McCullick, B., \& Mason, I. (2006). The development of expert coaching. In R. Jones (Ed.), The sports coach as teacher: Reconceptualising sports coaching (pp. 145-161). London: Routledge.

Schempp, P., McCullick, B., Pierre, P.S., Woorons, S., You, J., \& Clark, B. (2004). Expert golf instructors' student-teacher interaction patterns. Research Quarterly for Exercise and Sport, 75, 60-70.

Schempp, P., McCullick, B.A., Busch, C.A., Webster, C., \& Mason, I.S. (2006). The selfmonitoring of expert sport instructors. International Journal of Sports Science \& Coaching, 1, 25-35.

Schempp, P., Templeton, C., \& Clark, B.Farrally, M., \& Cochran, A.J. (1998). The knowledge acquisition of expert golf instructors. In M. Farrally \& A. J. Cochran (Eds.), Science and golf III: Proceedings of the world scientific congress of golf (pp. 295-301). Leeds: Human Kinetics.

Schmidt, R. A., \& Bjork, R. A. (1992). New conceptualizations of practice: Common principles in three paradigms suggest new concepts for training. Psychological Science, 3, 207-217.

Smith, D. J. (2003). A framework for understanding the training process leading to elite performance. Sports Medicine, 33, 1103-1126.

Sparkes, A. C. (1998). Validity in qualitative inquiry and the problem of criteria: Implications for sport psychology. The Sport Psychologist, 12, 363-386. 
835 Wiersma, L. D. (2001). Conceptualization and development of the sources of enjoyment in youth sport questionnaire. Measurement in Physical Education and Exercise Science, 5, 153-177. doi: 10.1207/s15327841mpee0503_3 methodological Promised Land? Evaluating the validity of cognitive interviews. In M. G. Sirken, D. J. Hermann, S. Schechter, N. Schwarz, J. M. Tanur \& R. Tourangeau (Eds.), Cognition and research (pp. 133-153). New York: Wiley. 
Table 1. Technical Change Practices Employed in Expert Golf Coaching

\begin{tabular}{lll}
\hline Umbrella Theme & Lower-order Theme & Raw Data Codes \\
\hline $\begin{array}{l}\text { Reported systems for } \\
\text { technical change }- \text { inter- }\end{array}$ & Stages & $1(n=2)$ \\
individual differences & & $2(n=3)$ \\
& & $3(n=2)$ \\
& & $9(n=1)$ \\
& & $9(n=1)$ \\
& Mechanisms & Psychological $(n=4)$ \\
& & Physiological $(n=3)$ \\
Intra-individual differences & Internal inconsistency & Psychosocial $(n=2)$ \\
in exemplar case studies & & Multi-directional $(n=2)$ \\
& & Constantly novel $(n=1)$ \\
Facilitation of pressure & Remedial approaches & Cyclical $(n=4)$ \\
resistance & & Incomplete $(n=3)$ \\
& & Reassurance $(n=4)$ \\
& & Focus of attention $(n=5)$ \\
\hline
\end{tabular}

Table 2. Methods Employed to Prevent Technical Failure Under Pressure.

\begin{tabular}{lc}
\hline \multicolumn{1}{c}{ Method } & $\boldsymbol{n}(\boldsymbol{\%})$ \\
\hline Repetition of the movement & $20(22.5)$ \\
Skills tests & $8(9.0)$ \\
Visualization/mental rehearsal & $5(5.6)$ \\
Trigger words/cues & $3(3.4)$ \\
Playing competitive golf & $3(3.4)$ \\
Pre-shot routine & $2(2.2)$ \\
Feeling confident/committed & $2(2.2)$ \\
Playing for financial incentive & $2(2.2)$ \\
Strength and conditioning & $1(1.1)$ \\
Simulating pressure & $1(1.1)$ \\
Video comparison before and after change & $1(1.1)$ \\
\hline
\end{tabular}

